\title{
Knowledge, Attitude and Practices about Colostrum Feeding among Pregnant Women in Military Hospital Rawalpindi of Pakistan
}

\author{
Rifat Aisha1, Fakhar Batool'1, Saema Sultana ${ }^{2}$ \\ ${ }^{1}$ College of Nursing, AFPGMI, RWP \\ ${ }^{2}$ College of Nursing, PIMS, Islamabad, Pakistan \\ Email: fakharbatool@gmail.com
}

Received 28 December 2015; accepted 25 April 2016; published 28 April 2016

Copyright (C) 2016 by authors and Scientific Research Publishing Inc.

This work is licensed under the Creative Commons Attribution International License (CC BY). http://creativecommons.org/licenses/by/4.0/

(c) (i) Open Access

\begin{abstract}
Background: It is well known that colostrum is important for promoting health, growth and development of the newborn, and it also helps to prevent against the infections. Breast feeding is a common practice in Pakistan but the importance of colostrums feeding is still poorly understood due to cultural variations. Objectives: The objectives are to assess the knowledge about the importance of colostrums feeding and to promote the practice of colostrums feeding in pregnant women. Methods: Data collection was done through semi-structured questionnaire regarding colostrum feeding among pregnant women. Gynaecology and Obstetrics Outpatient Department (OPD) and Antenatal Ward of Military Hospital Rawalpindi were selected for study purpose. Results: This study showed that $65 \%$ of women heard about colostrums from various sources like media, family and friends, and $35 \%$ heard from the health professional during antenatal visits. Only $6 \%$ of women knew that it is nutritious milk for the new born. Only women $(9 \%)$ were aware about its protective effects and had knowledge that it helps to improve the growth of the babies and fight against infections. $35 \%$ of women perceived that there is something harmful which is not good for the newborn while $25 \%$ of women asked that this is the milk to be fed to baby and $15 \%$ of women asked this the milk to be discarded before feeding. There were still many women (39\%) who lacked knowledge about colostrum, only $14 \%$ of the women in this study knew that the appropriate time for feeding colostrum is immediately after birth $(1 / 2-1$ hour $)$, whereas $86 \%$ of women starts feeding after 6 - 24 hrs. Majority of them who came from the rural areas were uneducated. Conclusion: Many women were aware about the importance of colostrum but the data still indicate that further efforts are required to improve the Knowledge, Attitude and Practice of colostrums feeding.
\end{abstract}

\section{Keywords}

Knowledge, Attitude, Practices and Colostrum 


\section{Introduction}

The colostrum feeding has significant effects for immediate and future health of newborn infants especially in developing countries such as Ethiopia that have high rates of malnutrition, infectious diseases and mortality for children under the age of 5 years [1] [2]. Exclusive breast-feeding from birth to 6 months of age has prolonged health benefits and emotional bonding for mother and child and is associated with lower infant morbidity and mortality rate, and better growth \& development of the baby [3].

Colostrum is the first milk produced by the mammary glands of mammals in late pregnancy just prior to giving birth and continuing through the early days of breastfeeding [4]. Colostrum is very rich in proteins, carbohydrates, vitamin A, and sodium chloride, but contains lower amounts of lipids and potassium than normal milk [5]-[7]. It also encourages the passage of stool. This helps to clear excess bilirubin which is produced in large quantities at birth and helps prevent jaundice. It contains various immunoglobulins like IgA (reactive to Escherichia coli virulence associated proteins) [8], IgG and IgM [9]. Other immune components of colostrum are lactoferrin, lysozyme, lactoperoxidase, complement and protein rich peptide (PRP). It also contains various cytokines and growth factors. PRP helps to fight against various viral infections like herpes viruses and HIV, bacterial and viral infections which are difficult to treat, various cancer, asthma, allergies and autoimmune diseases. It helps to reduce one of the leading causes of death in our country like diarrhoea and ARI [10].

There are many other qualities of colostrum that make it truly unique. Colostrum contains high amounts of sodium, potassium, chloride, and cholesterol. This combination is believed to encourage optimal development of the infant's heart, brain, and central nervous system. This may account for the prolonged secretion of colostrum in mothers who deliver their babies prematurely. All these components offer premature infants the best chance for the optimal development of their fragile organs [11].

Unfortunately colostrum feeding is not given to newborn for various societal myths and misconception. In a false belief of gutty honey, sugar water, glucose, and mishri water were fed as pre-lacteal feeds [12]. These manmade problems affect directly and indirectly health of newborn infants and cause malnutrition and high mortality rate in infants. This cross sectional study was undertaken to evaluate the awareness, knowledge and practices regarding the importance of clostrum feeding in Rawalpindi, Pakistan.

\section{Methodology}

It is a cross-sectional study, conducted in Combined Military Hospital and Military Hospital from January 2014-Oct 2014. 150 mothers were delivered during this period. Among them 150 were primi mothers and 100 were second para. 100 of them who were willing to participate and meeting the inclusion criteria were selected for study purpose, the information regarding practice of exclusive breast feeding and introducing complementary feeds was obtained only from second para mothers. A pre-tested questionnaire was used to carry out the study. After collection of data, information gathered was entered into SPSS version 18 \& analyzed by using percentage/proportions and presented in suitable tabular and graphical forms

The sampling was based on the following inclusion and exclusion criteria. (i) Inclusion Criteria: Mothers who already delivered their baby and those with a child who is below 5 years old and willing to participate were included in this survey. (ii) Exclusion Criteria: Pregnant women unwilling to participate, having a child with any kind of malformations and are above 5 years old were excluded. A voluntary written informed consent was taken from the participants in the language that the participant could understand and comprehend prior to the data collection

The study was conducted as per recommendations of Helsinki Declaration. Ethical approval was obtained from Ethical Review Committee (ERC) and Institutional consent was taken from the respective authority. They were offered support and given the choice to discontinue the interview for the time being. Moreover, they have an option to refuse to answer any question. However, none of the participants opted to discontinue or refused to answer any question

\section{Results}

Table 1 shows the demographic data of the participants 100 antenatal mothers were interviewed during the study period, majority of them were between the age of 18 - 40 years. The mean age of the participants was 26.7 
Table 1. Demographic data.

\begin{tabular}{ccc}
\hline Total $N=100$ & Demographic data & $\%$ ages \\
\hline Age of participants & $18-25$ & $60.0 \%$ \\
& $25-40$ & $40.0 \%$ \\
Education status & Illiterate & $63.0 \%$ \\
& literate & $37.0 \%$ \\
Occupation & House wives & $77.0 \%$ \\
& Employed & $23.0 \%$ \\
Number of children & Primi para & $65.0 \%$ \\
& Multi para & $45.5 \%$ \\
\hline
\end{tabular}

years. $63 \%$ of the women were iliterate and $37 \%$ were literat. $77.0 \%$ of them were house wife where as $23 \%$ women were working in different fields, $45.5 \%$ had previously delivered a baby. $65.0 \%$ have become pregnant for the first time.

Figure 1 represents about 90\% women have heard about colostrum among which 15\% received information through media. 30\% got to know about it from family and friends. Antenatal visits helped 35\% of them, and $10 \%$ of women got to know about it from other sources and $10 \%$ of them did not know about colostrum feeding.

Figure 2 highlights the myths and misconception of women regarding colostrum feeding. $40 \%$ women answered that breast milk is not enough to satisfy the baby, $37 \%$ said that gutty is the part of our tradition and better than first milk, $12 \%$ women said due to nipple pain they don't like to feed. $6 \%$ women said that baby is not able to suck properly and not satisfied and $6 \%$ women said that they do not like the colour of colostrum and need to give supplement feeding. . We have lower percentage of women who have knowledge on the importance of colostrum compared to few other studies done in this region.

Figure 3 shows the knowledge of the mother regarding the importance of clostrum feeding. 10\% women answered that this is just a $15 \%$ asked first breast milk to be discarded, only $25 \%$ women said that this is the milk to be fed the new born, whether $35 \%$ women perceived that there is something which is harmful for the new born, only $15 \%$ women asked that there is something extra for good health and it also prevent the neonate from infectious diseases.

Figure 4 represents that only $14 \%$ percent of the women knew that the appropriate time for feeding colostrum is immediately after the birth (1/2 - 1 hour), Where as $86 \%$ of women starts feeding within 6 - 24 hrs. There is a huge gap in the practices of colostrum feeding. Special attention is needed by the health care workers for pregnant women.

\section{Discussion}

A study was conducted by Joshi and his fellows In Nepal. Regarding the importance of colostrum to child's health, in this study $41 \%$ women believed that it helps for proper growth of child and fights against infection, $27 \%$ perceived it adds to good health $31 \%$ women had no knowledge about colostrum and only 1 woman thought it has bad effect to the child's health, In our study only 15 women knew that colostrum feeding could help the baby in fighting against infections. These findings highlight the need to give greater attention towards the women's health and well-being of pregnant women. We have lower percentage of women who have knowledge on the importance of colostrum compared to few other studies done in this region. There is an intense need to improve the knowledge of the women about feeding of clostrum through different awareness programs. 
Sources of information about colostrum

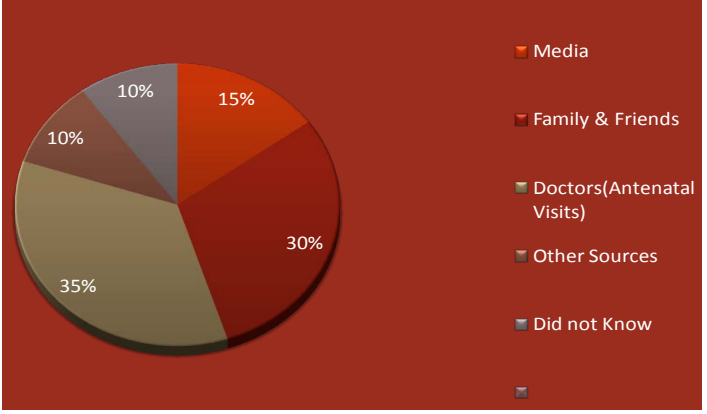

Figure 1. Knowledge, attitude and practice.

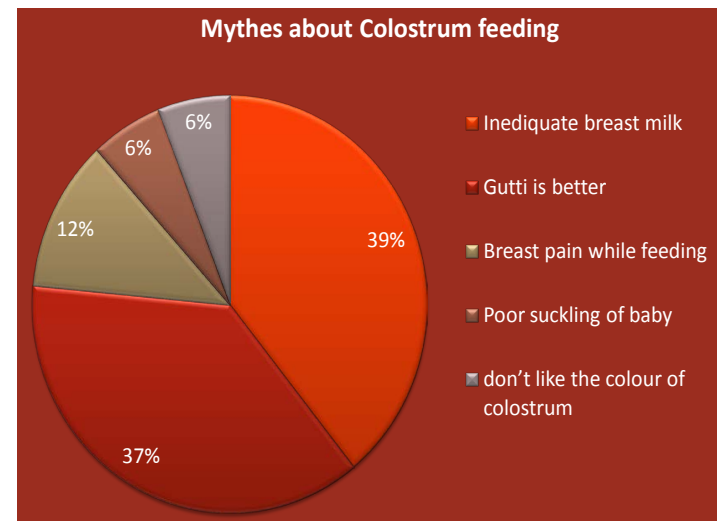

Figure 2. Myths and misconceptions.

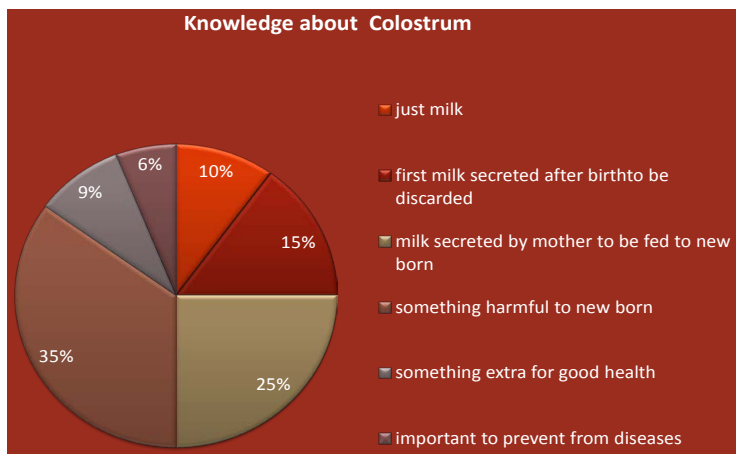

Figure 3. Knowledge about colostrums.

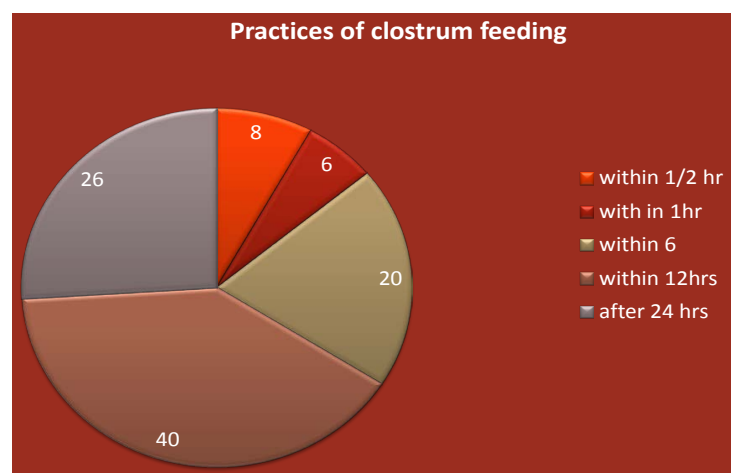

Figure 4. Practices of colostrums. 


\subsection{Outcome \& Utilization of Study}

This study will help in spreading knowledge, attitude and practices of colostrum feeding among general population as well as to create awareness regarding its importance.

\subsection{Recommendations}

Information related to the clostrum feeding should be provided through health care providers and the media.

Educational sessions should be arranged not only for the pregnant women.

Media can play a vital role in this regard.

Counseling services can be provided at work setting.

Information's should be provided through local magazines \& pamphlet in OPDs in local languages for the awareness of the society.

$\square$ Researches should be funded by the funding agencies.

\section{Conclusion}

Most of the women were not aware about the importance of colostrum, the data still indicate that further efforts are needed to improve the Knowledge, Attitude and Practice of colostrum feeding. Further awareness programs should be arranged to improve the Knowledge, Attitude and Practice of colostrum feeding in Pakistan.

\section{References}

[1] Silva, P. (2005) Environmental Factors and Children’s Malnutrition in Ethiopia: Policy Research. Working Paper Series No. 3489, The World Bank, Washington DC.

[2] Alemayehu, T., Haidar, J. and Habte, D. (2009) Determinants of Exclusive Breastfeeding Practices in Ethiopia. Ethiopian Journal of Health Development, 23, 12-18. http://dx.doi.org/10.4314/ejhd.v23i1.44832

[3] Mannel, R., Martens, P. and Walker, M., Eds. (2007) Core Curriculum for Lactation Consultant Practice. 2nd Edition, Jones and Bartlett Publishers, Sudbury, MA.

[4] La Leche League International. What Is Colostrum? How Does It Benefit My Baby? http://www.llli.org/faq/colostrum.html

[5] Ghai, O.P., Paul, V.K. and Bagga, A. (2009) Textbook of Paediatrics. 7th Edition, CBC Publisher and Distributors, New Delhi, 768.

[6] Heather Fisher Senior Thesis Project (2000) Colostrum: Properties, Functions, and Importance: The Relationship between the Immunoglobulin Concentration in Holstein Colostrum and the Total Senlm Protein in Holstein Heifer Calves.

[7] Science Daily (Homepage on the Internet). Colostrum. http://www.sciencedaily.com/articles/c/colostrum.html

[8] Loureiro, I., Frankel, G., Adu-Bobie, J., Dougan, G., Trabulsi, L.R. and Carneiro-Sampaio Magda, M.S. (1998) Human Colostrum Contains IgA Antibodies Reactive to Enteropathogenic Escherichia coli Virulence-Associated Proteins: Intimin, BfpA, EspA, and EspB. Journal of Pediatric Gastroenterology \& Nutrition, 27, 166-171. http://dx.doi.org/10.1097/00005176-199808000-00007

[9] Arifeen, S., Black, R.E., Antelman, G., Baqui, A., Caulfield, L. and Becker, S. (2001) Exclusive Breastfeeding Reduces Acute Respiratory Infection and Diarrhoea Deaths among Infants in Dhaka Slums. Pediatrics, 108, e67. http://dx.doi.org/10.1542/peds.108.4.e67

[10] Oddy, W. (2002) The Impact of Breast Milk on Infant and Child Health. Breastfeeding Review, 10, 5-18.

[11] United Nations Children's Fund. The State of the World's Children 2013: Children with Disabilities. Three United Nations Plaza, New York.

[12] UNICEF (2009) The Baby Friendly Hospital Initiative. http://www.unicef.org/newsline/tenstps.htm 